\title{
Health worker knowledge of Integrated Disease Surveillance and Response standard case definitions: a cross-sectional survey at rural health facilities in Kenya
}

\author{
Mitsuru Toda ${ }^{1 *}$ (D), Dejan Zurovac ${ }^{2,3}$, Ian Njeru' ${ }^{4}$ David Kareko ${ }^{4}$, Matilu Mwau ${ }^{5}$ and Kouichi Morita ${ }^{6}$
}

\begin{abstract}
Background: The correct knowledge of standard case definition is necessary for frontline health workers to diagnose suspected diseases across Africa. However, surveillance evaluations commonly assume this prerequisite. This study assessed the knowledge of case definitions for health workers and their supervisors for disease surveillance activities in rural Kenya.

Methods: A cross-sectional survey including 131 health workers and their 11 supervisors was undertaken in two counties in Kenya. Descriptive analysis was conducted to classify the correctness of knowledge into four categories for three tracer diseases (dysentery, measles, and dengue). We conducted a univariate and multivariable logistic regression analyses to explore factors influencing knowledge of the case definition for dysentery.

Results: Among supervisors, $81.8 \%$ knew the correct definition for dysentery, 27.3\% for measles, and no correct responses were provided for dengue. Correct knowledge was observed for $50.4 \%$ of the health workers for dysentery, only $12.2 \%$ for measles, and none for dengue. Of 10 examined factors, the following were significantly associated with health workers' correct knowledge of the case definition for dysentery: health workers' cadre (aOR 2.71;95\% Cl 1.20-6.12; $p=0.017$ ), and display of case definition poster (aOR 2.24; 95\% Cl 1.01-4.98; $p=0.048$ ). Health workers' exposure to the surveillance refresher training, supportive supervision and guidelines were not significantly associated with the knowledge.

Conclusion: The correct knowledge of standard case definitions was sub-optimal among health workers and their supervisors, which is likely to impact the reliability of routine surveillance reports generated from health facilities.
\end{abstract}

Keywords: Case definitions, Knowledge, Health workers, Disease surveillance, Kenya

\section{Background}

The first step in disease surveillance for frontline health workers is to diagnose and identify cases at health facilities. Rural health facilities in sub-Saharan Africa lack capacities to diagnose diseases through laboratory confirmations and health workers rely on clinical signs and symptoms to diagnose suspected cases of priority diseases. Validated clinical standard case definitions help standardize diagnosis of suspected cases across health workers within and across nations, and it is crucial for

\footnotetext{
* Correspondence: mitsuru@post.harvard.edu

${ }^{1}$ Nagasaki University Institute of Tropical Medicine, KEMRI-NUITM, Kenyatta

Hospital Grounds, Nairobi, Kenya

Full list of author information is available at the end of the article
}

implementing the International Health Regulations 2005 [1-3]. In addition, standard case definitions are important for managers at all levels to monitor epidemic trends across health facilities, investigate epidemic alerts, respond to potential outbreaks, and plan activities related to disease surveillance and control.

In Kenya as in other African countries, the World Health Organization regional office for Africa (WHOAfro) implemented the Integrated Disease Surveillance and Response (IDSR) strategy [4,5], which promotes the use of IDSR standard case definitions which are stipulated in technical guidelines, promoted through job aids, and included in the in-service training programs. In IDSR evaluation literature, processes of disease surveillance and 
activities supporting implementation have commonly been examined [6-17]. However, the knowledge of IDSR standard case definitions by health workers and their supervisors have been assumed and no study has examined the awareness and knowledge of case definitions as stipulated in the guidelines $[18,19]$. We therefore conducted a cross-sectional study among frontline health workers and their disease surveillance supervisors in rural Kenya to assess their knowledge of IDSR standard case definitions.

\section{Methods}

A cross-sectional survey was conducted as part of the mSOS (mobile Short-message-service based disease Outbreak alert Systems) trial [20], which measured the effectiveness of an intervention using text-message disease outbreak alert system. The study took place at rural health facilities and sub-county management offices in Busia and Kajiado counties in Kenya.

\section{Description of study area}

Busia County is by the Victoria Lake basin and borders Uganda, and Kajiado County borders Tanzania. In the two counties, there are 143 functional health facilities belonging to 11 sub-counties. All health facilities are expected to report priority diseases through IDSR strategy to disease surveillance coordinators at the subcounty level. IDSR strategy was introduced to health workers in the two counties in 2005. Health facility incharges, or IDSR focal persons at each health facility are required to send routine paper-based reports on priority diseases to sub-county office on immediate and weekly basis. Sub-county level disease surveillance coordinators are expected to monitor disease trends, respond to alerts of disease surveillance activities, and provide support supervision to the health facilities. Use of standard case definition has been promoted through the IDSR strategy in the area for over a decade. In addition, in September and October 2013, health facility in-charges in the study area attended an IDSR refresher training organized by the Ministry of Health. During the 1-day training, IDSR case definitions and reporting requirements were highlighted. Each participant was given the IDSR technical guidelines for use at their health facility, and participants were expected to have refreshed their knowledge on IDSR standard case definitions.

\section{Participants and data collection}

Of 143 health facilities, 12 health facilities were excluded from the study because the facilities were closed on the day of the survey. Participants included 131 health facility in-charges and 11 sub-county disease surveillance coordinators who were interviewed by the study team in April 2014, which was 6 months after the IDSR refresher training took place in the study area. Open-ended questionnaires were self-administered by health facility in-charge and their sub-county supervisors at their respective workstations on their knowledge of IDSR standard case definitions. The questionnaires were pre-tested in Nairobi prior to study collection. National level Ministry of Health staff members at the Disease Surveillance and Response Unit, who are well experienced and trained in IDSR strategy, supervised the collection of data at each study facility. The responses were recorded in English because it is the language for pre- and in- service trainings in Kenya.

\section{Selection of tracer diseases and study definition}

Three tracer diseases, dysentery, measles and dengue, were selected for analysis based on the epidemiological interest [21] and the complexity of the IDSR standard case definitions (Table 1). Dysentery was selected because the disease occurs frequently [22-24] and has only 2 simple key components in the case definition. Measles was selected because there are sporadic outbreaks in the country $[25,26]$ and has slightly more complex case definition than dysentery containing 5 key components. Dengue was selected because the disease is reported frequently in the research setting [27-34] and has a complex case definition containing 8 key components. All of the three tracer diseases require weekly reporting according to the national IDSR guidelines, while measles and dengue are also required to be reported immediately through the case-based reports as suspected cases are detected. Table 1 presents study definitions for each of the three tracer diseases by four categorization of the correctness: correct, partially correct, incorrect, and "do not know". Responses were classified as correct when all key components were stated without other signs or symptoms. Partial correctness was defined as mentioning all of the key components, or mentioning some of key components with additional disease related symptoms. Incorrect responses were defined as mentioning only one or none of the key components. Finally, the last category "do not know" included answers where respondents did not mention any signs or symptoms.

\section{Data analysis}

Data were double entered using Base (LibreOffice 5, The Document Foundation, Berlin, Germany). Study investigators verified data manually comparing paper based questionnaires. During the coding process, we classified key words of signs and symptoms according to our study definitions for the three tracer diseases. Certain key words were included as synonyms, such as diarrhea and watery stool; eye discharge, red eyes and conjunctivitis; funny nose and coryza; pain in the eyes and retro-orbital pain; general pain, muscle pain and myalgia; joint pain and arthralgia; and low blood cells and leukopenia. 
Table 1 Standard case definitions according to IDSR national guidelines and study classifications

\begin{tabular}{|c|c|c|c|}
\hline & $\begin{array}{l}\text { Standard case definitions (suspected case) in the } \\
\text { IDSR technical guidelines }\end{array}$ & Study definitions & ased on key words \\
\hline \multirow[t]{4}{*}{ Dysentery (Shigella) } & \multirow[t]{4}{*}{ A person with diarrhoea with visible blood in stool } & Correct & Diarrhea and blood \\
\hline & & Partially correct & Diarrhea, blood, and other related symptoms ${ }^{1}$ \\
\hline & & Incorrect & No mention of diarrhea or blood \\
\hline & & Do not know & No mention of signs and symptoms \\
\hline \multirow[t]{4}{*}{ Measles } & \multirow{4}{*}{$\begin{array}{l}\text { Any person with fever and maculopapular } \\
\text { (non-vesicular) generalized rash and any } \\
\text { one of the following: cough, coryza } \\
\text { (irritation and inflammation of the } \\
\text { mucosal membrane of the nose), } \\
\text { conjunctivitis (red eyes), any person } \\
\text { in whom a clinician suspects measles }\end{array}$} & Correct & Fever, rash, cough, coryza, and conjunctivitis \\
\hline & & Partially correct & $\begin{array}{l}\text { Fever, rash, and at least one of the following } \\
\text { symptoms: cough, coryza, and conjunctivitis; } \\
\text { with or without related symptoms }\end{array}$ \\
\hline & & Incorrect & No mention of rash or fever \\
\hline & & Do not know & No mention of signs and symptoms \\
\hline \multirow[t]{4}{*}{ Dengue fever } & \multirow{4}{*}{$\begin{array}{l}\text { Any person with acute febrile illness of } \\
2-7 \text { days duration with } 2 \text { or more of the } \\
\text { following: headache, retro-orbital pain } \\
\text { (pain behind the eyes), myalgia (muscle pain), } \\
\text { arthralgia (joint pain), rash, haemorrhagic } \\
\text { manifestations, leukopenia (low white blood cells) }\end{array}$} & Correct & $\begin{array}{l}\text { Fever, headache, retro-orbital pain, myalgia, } \\
\text { arthralgia, rash, hemorrhagic manifestations, } \\
\text { and leukopenia }\end{array}$ \\
\hline & & Partially correct & $\begin{array}{l}\text { Fever and at least two of the following } \\
\text { symptoms: headache, retro-orbital pain, } \\
\text { myalgia, arthralgia, rash, hemorrhagic } \\
\text { manifestations, and leukopenia }\end{array}$ \\
\hline & & Incorrect & $\begin{array}{l}\text { No mention of fever; or mention of fever } \\
\text { with less than two of the following symptoms: } \\
\text { headache, retro-orbital pain, myalgia, arthralgia, } \\
\text { rash, hemorrhagic manifestations, and leukopenia }\end{array}$ \\
\hline & & Do not know & No mention of signs and symptoms \\
\hline
\end{tabular}

${ }^{1}$ Other related symptoms include: abdominal pain/cramps, fever, and frequency of diarrhea in a day

Descriptive analysis of IDSR standard case definition was conducted to categorize the correctness of knowledge of three tracer diseases. To explore factors influencing the knowledge of IDSR standard case definition, we focused on dysentery because the variability of correct responses was observed only for this tracer disease. We first conducted a univariate analysis and estimated odds ratios (OR), $p$-values, and $95 \%$ confidence intervals (CIs) for the association between 10 broad factors and correct dysentery knowledge outcome. The 10 factors included health worker and health facility characteristics. In specific, location and size of facility (dispensaries: government funded health facility that provides primary healthcare services, maternity homes: private or NGO funded health facility that cares for pregnant women, medical clinics: private health facility that provides primary healthcare services, and nursing homes: private or NGO funded health facility that cares for the elderly), availability of IDSR focal person at facility, age, gender, qualification (nurses: licensed medical practitioner with 3-4 years of pre-service training, clinical officer: licensed medical practitioner with 3-4 years of pre-service training, and medical doctor: licensed medical practitioner with 6 years of pre-service training), and exposure to IDSR interventions by health workers. Factors with $p$-value $<0.2$ were then entered into multivariable model. We also explored two-way interaction terms of 4 variables related to disease surveillance interventions. The variables were: exposure to training, availability of guidelines, availability of poster, and support supervision. None of these 4 factors in the interaction terms were statistically significant at 0.05 level and we did not include the interaction terms in the model. Analysis was performed using Stata version 14 (StataCorp, College Station, TX, USA). Hypothesis testing and CI estimation were completed with alpha level of 0.05 .

\section{Results}

Characteristics of health workers and their supervisors

Of 11 supervisors interviewed, 7 were from Busia (64.6\%). All were public health officers. Nearly all disease surveillance coordinators were male (90.9\%) and the median age of the coordinators was 44 years [IQR 38-46]. Of 131 respondents (Table 2), nearly $40 \%$ were from Busia (36.6\%). Most commonly, they worked at dispensaries (70.2\%). Nearly two-thirds (64.1\%) worked at government-owned public facilities, and over two-thirds (69.5\%) worked at health facilities with an IDSR focal person. Half of the respondents were female $(51.9 \%)$ and the median age of the respondents was 36 years [IQR $30-48]$. The majority were nurses (70.2\%). Around $20 \%$ were clinical officers, who are clinicians with 3 years of pre-service training (20.6\%). Regarding the surveillance related interventions, over two-thirds (68.7\%) had IDSR case definition poster displayed, observed by study data collectors. Most of the respondents (74.1\%) had received 
Table 2 General characteristics of health facility workers

\begin{tabular}{|c|c|}
\hline$N=131$ & n (\%) \\
\hline \multicolumn{2}{|l|}{ County } \\
\hline Busia & $48(36.6)$ \\
\hline Kajiado & $83(63.4)$ \\
\hline \multicolumn{2}{|l|}{ Health facility level } \\
\hline Hospital & $10(7.6)$ \\
\hline Health centre & $29(22.1)$ \\
\hline Dispensary $^{a}$ & $92(70.2)$ \\
\hline \multicolumn{2}{|l|}{ Health facility ownership } \\
\hline Public & $84(64.1)$ \\
\hline Private & $28(21.4)$ \\
\hline $\mathrm{NGO} / \mathrm{FBO}$ & $19(14.5)$ \\
\hline Working at health facility with IDSR focal person & $91(69.5)$ \\
\hline Age; median $[\mathrm{QQR}]^{\mathrm{b}}$ & $36[30-48$ \\
\hline \multicolumn{2}{|l|}{ Gender } \\
\hline Female & $68(51.9)$ \\
\hline Male & $63(48.1)$ \\
\hline \multicolumn{2}{|l|}{ Qualification } \\
\hline Nurse & $92(70.2)$ \\
\hline Clinical officer & $27(20.6)$ \\
\hline Medical doctor & $2(1.5)$ \\
\hline Other cadre ${ }^{c}$ & $10(7.6)$ \\
\hline \multicolumn{2}{|l|}{ Exposure to disease surveillance interventions } \\
\hline Availability of poster & $90(68.7)$ \\
\hline Availability of guidelines & $20(15.3)$ \\
\hline Received support supervision in the last 6 months & $97(74.1)$ \\
\hline Attended training in 2013 & $80(61.1)$ \\
\hline
\end{tabular}

Includes: 18 medical clinics, 3 maternity homes, and 6 nursing homes

${ }^{b}$ Excludes 2 health worker with missing age information

'Other includes: 1 Community Health Extension Worker, 1 health records

officer, 1 public health officer, 1 Prevention of Mother to Child Transmission

worker, and 6 laboratory technician/technologist

Abbreviations

$C O$ clinical officer, $F B O$ faith-based organization, IDSR integrated disease surveillance and response, $I Q R$ interquartile range, $M D$ medical doctor, NGO

non-governmental organization

at least one support supervision visit on surveillance related matters in the past 6 months. Finally, only 15.3\% had access to IDSR technical guidelines at their facility, while the majority (61.1\%) attended the IDSR refresher training conducted by the study team 6 months earlier (Table 2).

\section{Knowledge of IDSR case definitions}

Table 3 describes the knowledge of three tracer diseases by health workers and their supervisors. Of 11 supervisors, $81.8 \%$ knew the correct definition for dysentery, $27.3 \%$ for measles, and no correct responses were provided for dengue. For measles, $36.4 \%$ responded partially correctly and
Table 3 Respondents' knowledge of IDSR standard case definitions

\begin{tabular}{llll}
\hline & $\begin{array}{l}\text { Dysentery } \\
\mathrm{n}(\%)\end{array}$ & $\begin{array}{l}\text { Measles } \\
\mathrm{n}(\%)\end{array}$ & $\begin{array}{l}\text { Dengue } \\
\mathrm{n}(\%)\end{array}$ \\
\hline $\begin{array}{l}\text { Sub-county disease surveillance coordinator } \\
\mathrm{N}=11\end{array}$ & & \\
$\begin{array}{l}\text { Correct } \\
\text { Partially correct }\end{array}$ & $9(81.8)$ & $3(27.3)$ & 0 \\
Incorrect & $1(9.1)$ & $4(36.4)$ & $1(9.1)$ \\
Do not know & $1(9.1)$ & $3(27.3)$ & $5(45.5)$ \\
Health facility in-charges \\
$\begin{array}{l}\text { N=131 } \\
\text { Correct }\end{array}$ & $1(9.1)$ & $5(45.5)$ \\
Partially correct & $23(17.6)$ & $54(41.2)$ & $5(3.8)$ \\
Incorrect & $22(16.8)$ & $36(27.5)$ & $41(31.3)$ \\
Do not know & $20(15.3)$ & $25(19.1)$ & $85(64.9)$ \\
\hline
\end{tabular}

$27.3 \%$ incorrectly. For dengue, only one supervisor provided partially correct response $(9.1 \%)$, nearly half responded incorrectly $(45.5 \%)$, and the remaining $45.5 \%$ did not know the definition (Table 3).

Health workers displayed similar patterns as their supervisors across the three tracer diseases. Correct knowledge was observed for $50.4 \%$ of the health workers for dysentery, for only $12.2 \%$ for measles, and none of the health workers provided correct case definition for dengue. For dysentery, $17.6 \%$ responded partially correctly where bloody diarrhea was mentioned but also additional dysentery related signs and symptoms such as pain or cramps $(11 / 23)$ and fever (3/23). Furthermore, twenty-two health workers (16.8\%) provided incorrect case definitions by either omitting diarrhea (16/22) or blood (6/22). Finally, the remaining 20 health workers $(15.3 \%)$ did not know the definition for dysentery (Table 3 ).

For measles, less than half of health workers responded partially correctly (41.2\%) where health workers were able to mention fever and rash, but not all of the additional three components (cough, coryza, and conjunctivitis). Most commonly omitted symptoms were cough (37/54), followed by coryza (29/54), and conjunctivitis (12/54). Over one-quarter of health workers responded incorrectly (27.5\%) by omitting fever (29/36) followed by rash (12/ 36). The remaining $19.1 \%$ of the health workers did not know the case definition for measles (Table 3).

Nearly all (96.2\%) health workers either incorrectly stated or did not know the case definition for dengue. Among the incorrect responses, three did not mention fever $(3 / 41)$, while other dengue criteria were rarely mentioned: headache (9/41), arthralgia (8/41), hemorrhagic manifestations (6/41), retro-orbital pain $(2 / 41)$, and rash $(2 / 41)$, myalgia $(0 / 41)$, and leukopenia $(0 / 41)$. 


\section{Predictors influencing knowledge of dysentery}

We examined 10 factors that may influence the health facility in-charges' knowledge of dysentery. The following variables did not meet entrance criteria $(p<0.2)$ for the multivariable analysis: county (OR 1.11; $95 \%$ CI 0.55-2.27; $p=0.767$ ), smaller facilities (OR 1.47; 95\% CI $0.69-3.13, p=0.313$ ), age (OR 1.23; 95\% CI 0.62-2.47; $p$ $=0.553)$, gender (OR 1.09; 95\% CI 0.55-2.17; $p=0.796)$, training (OR 1.41; 95\% CI 0.70-2.86; $p=0.335$ ), presence of IDSR technical guidelines (OR 0.61; 95\% CI $0.23-$ $1.61 ; p=0.316$ ), and support supervision (OR $0.87 ; 95 \%$ CI $0.40-1.90 ; p=0.729$ ) (Table 4). The following factors were significantly associated with correct dysentery IDSR standard case definition knowledge in the multivariable analysis: health workers' cadre (aOR 2.71; 95\% CI 1.20 6.12; $p=0.017$ ), and display of case definition poster (aOR 2.24; 95\% CI 1.01-4.98; $p=0.048$ ). Although meeting the inclusion criteria for multivariable model, the presence of IDSR focal person at the health facility (aOR 1.83 ; 95\% CI $0.82-4.09 ; p=0.139$ ) was not significantly associated with correct dysentery knowledge (Table 4).

\section{Discussion}

Correct knowledge of standard case definitions is an important first step for successful implementation of any disease surveillance strategy. Our study, one of the first that examined and quantified the knowledge of IDSR standard case definitions in sub-Saharan Africa, revealed alarmingly low levels of knowledge in Kenya. Patient registers at health facilities are used as source document for evaluating disease surveillance reporting practices and health systems in general [35], and our study findings imply that the validity of the source documents may be overlooked. First, we found that knowledge of dengue is practically non-existent among health workers and their disease surveillance supervisors. We speculate that the relatively complex case definitions, lack of routine laboratory diagnosis to confirm dengue in rural health facilities, similarities with other mosquito-borne diseases such as malaria, and the possibility of perceived nonlethal nature of the disease may contribute to low knowledge. The findings are however not unique to our study sites since suboptimal knowledge of dengue has also been reported among health workers in high-income countries [36]. Similarly to dengue but even more surprising finding was found with respect to measles. Despite simple case definitions, only a quarter of supervisors and just one in ten health workers could state five clinical criteria, which have been promoted in Kenya over a decade. It should also be acknowledged that surveillance guidelines in Kenya include an ambiguous and unnecessary wording, "any person in whom a clinician suspects measles", which undermines the validity of promoted case definitions and itself precludes standardization. Similar sentiments were expressed in an evaluation conducted in South Sudan [37]. The most unexpected finding was observed on dysentery where only half of the health workers were able to correctly state the simple criteria of "bloody diarrhea." Health workers responses of other dysentery related symptoms such as "abdominal cramps and pains" may suggest the health workers are knowledgeable of the text book clinical features [38], but disregarding the IDSR guidelines.

Our predictor analysis examining factors for correct knowledge added further light on what may influence knowledge of dysentery. First, we found that nurses are significantly more knowledgeable compared to other cadres of health workers. One of the possible explanations is that health workers with greater pre-service clinical training are more likely to overrule guidelines, which has been shown in previous studies $[39,40]$. Second, the presence of a simple job aid in the form of a case definition poster at a health facility was significantly associated with better knowledge. Reminders are shown to be effective intervention in other studies [41], and policy makers should prioritize such seemingly simple intervention. In addition, this study was conducted in the context of evaluating a text message intervention to enhance disease surveillance reporting [20] and reminder interventions through such channels but targeting health workers should also be explored in the future. Finally, exposure to either refresher training or supervision was not associated with greater knowledge of case definition. We do not think that these interventions are ineffective per se, but perhaps the sub-optimal quality of the training and supervision intervention may have contributed to the analysis results. The study did not have a component to measure the quality of training or resources to follow-up supervision mechanisms after training, but we speculate that these factors may have contributed to low knowledge levels. Moreover, the low knowledge levels of disease surveillance supervisors found in this study further elevates the levels of challenges faced in the field to promote adherence to IDSR standard case definitions.

Several study limitations should be acknowledged. First, the knowledge levels were self-reported by health workers and the study did not examine whether the health workers' knowledge was translated into practice. We also did not examine the duration of professional experience that may have influenced the level of knowledge. Knowledge is however a prerequisite for correct practice and it is unlikely that health workers would adhere to guidelines. We also cannot confidently assume uniformity in diagnosis of suspected cases when knowledge of the standard case definition is not present. Second, we limited the analysis to three tracer diseases and applied a rather relaxed approach to interpreting the 
Table 4 Predictors influencing knowledge of dysentery: univariate and multivariable regression results

\begin{tabular}{|c|c|c|c|c|c|c|}
\hline & $N$ & n (\%) & $\begin{array}{l}\text { OR } \\
{[95 \% \mathrm{Cl}]}\end{array}$ & $p$-value & $\begin{array}{l}\text { aOR } \\
{[95 \% \mathrm{Cl}]} \\
\end{array}$ & $p$-value \\
\hline \multicolumn{7}{|c|}{ General characteristics } \\
\hline \multicolumn{7}{|l|}{ County } \\
\hline Busia & 48 & $25(52.1)$ & $1.11[0.55-2.27]$ & 0.767 & - & - \\
\hline Kajiado & 83 & $41(49.4)$ & 1.0 (Ref) & & - & \\
\hline \multicolumn{7}{|l|}{ Size of facility } \\
\hline Smaller ${ }^{a}$ & 92 & $49(53.3)$ & 1.47 [0.69-3.13] & 0.313 & - & - \\
\hline Larger $^{b}$ & 39 & $17(43.6)$ & 1.0 (Ref) & & - & \\
\hline \multicolumn{7}{|c|}{ IDSR focal person at facility } \\
\hline Available & 91 & $50(55.0)$ & $1.83[0.86-3.89]$ & 0.117 & 1.83 [0.82-4.09] & 0.139 \\
\hline Not available & 40 & $16(40.0)$ & 1.0 (Ref) & & 1.0 (Ref) & \\
\hline \multicolumn{7}{|l|}{$\mathrm{Age}^{\mathrm{c}}$} \\
\hline $35+$ years old & 71 & $38(53.5)$ & $1.23[0.62-2.47]$ & 0.553 & - & - \\
\hline 20-34 years old & 58 & $28(48.3)$ & 1.0 (Ref) & & - & \\
\hline \multicolumn{7}{|l|}{ Gender } \\
\hline Female & 68 & $35(51.5)$ & $1.09[0.55-2.17]$ & 0.796 & - & - \\
\hline Male & 63 & $31(49.2)$ & 1.0 (Ref) & & - & \\
\hline \multicolumn{7}{|l|}{ Qualification } \\
\hline Nurse & 92 & $53(57.6)$ & $2.72[1.24-5.95]$ & 0.012 & $2.71[1.20-6.12]$ & 0.017 \\
\hline MD/CO/other ${ }^{d}$ & 39 & $13(33.3)$ & 1.0 (Ref) & & 1.0 (Ref) & \\
\hline \multicolumn{7}{|c|}{ Exposure to IDSR interventions } \\
\hline \multicolumn{7}{|l|}{ Training } \\
\hline Attended & 80 & $43(53.8)$ & $1.41[0.70-2.86]$ & 0.335 & - & - \\
\hline Did not attend & 51 & $23(45.1)$ & 1.0 (Ref) & & - & \\
\hline \multicolumn{7}{|c|}{ Case definition poster } \\
\hline Displayed & 90 & $52(57.8)$ & $2.64[1.22-5.70]$ & 0.013 & $2.24[1.01-4.98]$ & 0.048 \\
\hline Not displayed & 41 & $14(34.2)$ & 1.0 (Ref) & & 1.0 (Ref) & \\
\hline \multicolumn{7}{|l|}{ Technical guidelines } \\
\hline Available & 20 & $8(40.0)$ & $0.61[0.23-1.61]$ & 0.316 & - & - \\
\hline Not available & 111 & $58(52.3)$ & 1.0 (Ref) & & - & \\
\hline \multicolumn{7}{|c|}{ Supervision in past 6 months } \\
\hline Received & 97 & $48(49.5)$ & $0.87[0.40-1.90]$ & 0.729 & - & - \\
\hline Not received & 34 & $18(52.9)$ & 1.0 (Ref) & & - & \\
\hline
\end{tabular}

Includes 65 dispensaries, 3 maternity homes, 18 medical clinics, and 6 nursing homes

b Includes 29 health centers and 4 hospitals

'The denominator excludes 2 health worker with missing age information

dOther includes: 1 Community Health Extension Worker, 1 health records officer, 1 public health officer, 1 Prevention of Mother to Child Transmission worker, and 6 laboratory technician/technologist

Abbreviations

$a O R$ adjusted odds ratio, $C O$ clinical officer, IDSR integrated disease surveillance and response, MD medical doctor

definitions. Given the low knowledge levels found overall in the study, stricter case definitions would have however yielded even lower knowledge results, and likely without changes to the interpretation of the findings. Third, the small sample size used in this study may have precluded showing significant associations when associations were truly present, and results should be interpreted with caution. Finally, while the study included a number of health workers from two areas in Kenya, the results are not nationally representative and cannot be generalized across the country.

\section{Conclusion}

Overall, the IDSR case definition knowledge needs to be further improved among both health workers and their supervisors, and the findings are likely to impact the 
reliability of routine surveillance reports generated from health facilities. The findings also suggest that simple intervention such as reminders are more effective than ad hoc trainings and routine supervision to ensure uniformed knowledge of case definitions. Further studies on examining effective methods of enhancing knowledge of IDSR standard case definitions are justified.

\section{Acknowledgements}

We thank the Disease Surveillance and Response Unit at the Ministry of Health in Kenya for their support on this study. We also thank the Kajiado and Busia County governments and the disease surveillance coordinators in the sub counties for their support. We are also grateful for the field interviewers and research assistants for their tireless work. This study is published with the permission of the Director of KEMRI.

\section{Funding}

The Japan International Cooperation Agency (JICA) and the Japan Agency for Medical Research and Development (AMED) supported this study under the Science and Technology Research Partnerships (SATREPS) project in Kenya (2012-2017). The funders had no role in study design, data collection and analysis, decision to publish, or preparation of the manuscript.

\section{Availability of data and materials}

The datasets used and/or analyzed during the current study are available from the corresponding author on reasonable request.

\section{Authors' contributions}

Conceived and designed experiments: MT DZ IN MM KM. Performed experiments: MT DK IN. Analyzed the data: MT DZ. Contributed to analysis tools: MT DZ DK IN. Wrote the paper: MT DZ DK IN MM KM. Critically reviewed the paper and approved the final version: MT DZ DK IN MM KM. Al authors read and approved the final manuscript.

\section{Ethics approval and consent to participate}

The Kenya Medical Research Institute (KEMRI) Ethical Review Committee (SSC 2523) provided ethical approval. Written informed consent was obtained from all participants.

\section{Consent for publication}

Not applicable.

\section{Competing interests}

The authors declare that they have no competing interests.

\section{Publisher's Note}

Springer Nature remains neutral with regard to jurisdictional claims in published maps and institutional affiliations.

\section{Author details}

'Nagasaki University Institute of Tropical Medicine, KEMRI-NUITM, Kenyatta Hospital Grounds, Nairobi, Kenya. ${ }^{2}$ Oxford University, Oxford, UK. ${ }^{3}$ Kenya Medical Research Institute-Wellcome Trust Research Programme, Nairobi, Kenya. ${ }^{4}$ Kenya Ministry of Health Disease Surveillance and Response Unit, Nairobi, Kenya. ${ }^{5}$ Kenya Medical Research Institute, Nairobi, Kenya. ${ }^{6}$ Nagasaki University Institute of Tropical Medicine, Nagasaki, Japan.

Received: 8 May 2017 Accepted: 3 January 2018

Published online: 17 January 2018

\section{References}

1. Baker MG, Fidler DP. Global public health surveillance under new international health regulations. Emerg Infect Dis. 2006;12:1058-65.

2. Fidler DP, Gostin LO. The new international health regulations: an historic development for international law and public health. J Law Med Ethics. 2006;34(85-94):84

3. Kasolo F, Yoti Z, Bakyaita N, Gaturuku P, Katz R, et al. IDSR as a platform for implementing IHR in African countries. Biosecur Bioterror. 2013;11:163-9.
4. Ministry of Public Health and Sanitation (2012) Integrated disease surveillance and response in Kenya: technical guidelines 2012

5. Perry HN, McDonnell SM, Alemu W, Nsubuga P, Chungong S, et al. Planning an integrated disease surveillance and response system: a matrix of skills and activities. BMC Med. 2007:5:24

6. Sow I, Alemu W, Nanyunja M, Duale S, Perry HN, et al. Trained district health personnel and the performance of integrated disease surveillance in the WHO African region. East Afr J Public Health. 2010;7:16-9.

7. Adokiya MN, Awoonor-Williams JK, Barau IY, Beiersmann C, Mueller O. Evaluation of the integrated disease surveillance and response system for infectious diseases control in northern Ghana. BMC Public Health. 2015;15:75.

8. Adokiya MN, Awoonor-Williams JK, Beiersmann C, Muller O. The integrated disease surveillance and response system in northern Ghana: challenges to the core and support functions. BMC Health Serv Res. 2015;15:288.

9. Adokiya MN, Awoonor-Williams JK, Beiersmann C, Muller O. Evaluation of the reporting completeness and timeliness of the integrated disease surveillance and response system in northern Ghana. Ghana Med J. 2016:50:3-8.

10. Lukwago L, Nanyunja M, Ndayimirije N, Wamala J, Malimbo M, et al. The implementation of integrated disease surveillance and response in Uganda: a review of progress and challenges between 2001 and 2007. Health Policy Plan. 2013:28:30-40.

11. Phalkey RK, Kroll M, Dutta S, Shukla S, Butsch C, et al. Knowledge, attitude, and practices with respect to disease surveillance among urban private practitioners in Pune, India. Glob Health Action. 2015;8:28413.

12. McDonnell SM, Perry HN, McLaughlin B, McCurdy B, Parrish RG. Information for disasters, information disasters, and disastrous information. Prehosp Disaster Med. 2007;22:406-13.

13. Mwatondo AJ, Ng'ang'a Z, Maina C, Makayotto L, Mwangi M, et al. Factors associated with adequate weekly reporting for disease surveillance data among health facilities in Nairobi County, Kenya, 2013. Pan Afr Med J. 2016;23:165.

14. Nnebue CC, Onwasigwe CN, Adogu PO, Onyeonoro UU. Awareness and knowledge of disease surveillance and notification by health-care workers and availability of facility records in Anambra state, Nigeria. Niger Med J. 2012;53:220-5

15. Nnebue CC, Onwasigwe CN, Ibeh CC, Adogu PO. Effectiveness of data collection and information transmission process for disease notification in Anambra state, Nigeria. Niger J Clin Pract. 2013;16:483-9.

16. Nsubuga P, Brown WG, Groseclose SL, Ahadzie L, Talisuna AO, et al, Implementing integrated disease surveillance and response: four African countries' experience, 1998-2005. Glob Public Health. 2010;5:364-80.

17. Nsubuga P, Eseko N, Tadesse W, Ndayimirije N, Stella C, et al. Structure and performance of infectious disease surveillance and response, United Republic of Tanzania, 1998. Bull World Health Organ. 2002;80:196-203.

18. Phalkey RK, Yamamoto S, Awate P, Marx M. Challenges with the implementation of an integrated disease surveillance and response (IDSR) system: systematic review of the lessons learned. Health Policy Plan. 2015:30(1):131-43.

19. Sahal N, Reintjes R, Aro AR. Review article: communicable diseases surveillance lessons learned from developed and developing countries: literature review. Scand J Public Health. 2009;37:187-200.

20. Toda M, Njeru I, Zurovac D, Tipo SO, Kareko D, et al. Effectiveness of a mobile short-message-service-based disease outbreak alert system in Kenya. Emerg Infect Dis. 2016:22:711-5.

21. Kebede S, Duales S, Yokouide A, Alemu W. Trends of major disease outbreaks in the African region, 2003-2007. East African journal of public health. 2010;7:20-9.

22. Njuguna C, Njeru I, Mgamb E, Langat D, Makokha A, et al. Enteric pathogens and factors associated with acute bloody diarrhoea, Kenya. BMC Infect Dis. 2016;16:477.

23. Pavlinac PB, Denno DM, John-Stewart GC, Onchiri FM, Naulikha JM, et al. Failure of syndrome-based diarrhea management guidelines to detect Shigella infections in Kenyan children. J Pediatric Infect Dis Soc. 2016;5:366-74.

24. Livio S, Strockbine NA, Panchalingam S, Tennant SM, Barry EM, et al. Shigella isolates from the global enteric multicenter study inform vaccine development. Clin Infect Dis. 2014;59:933-41.

25. Centers for Disease C, Prevention. Measles-horn of Africa, 2010-2011. MMWR Morb Mortal Wkly Rep. 2012;61:678-84.

26. Navarro-Colorado C, Mahamud A, Burton A, Haskew C, Maina GK, et al. Measles outbreak response among adolescent and adult Somali refugees displaced by famine in Kenya and Ethiopia, 2011. J Infect Dis. 2014;210:1863-70 
27. Were F. The dengue situation in Africa. Paediatr Int Child Health. 2012; 32(Suppl 1):18-21.

28. Blaylock JM, Maranich A, Bauer K, Nyakoe N, Waitumbi J, et al. The seroprevalence and seroincidence of dengue virus infection in western Kenya. Travel Med Infect Dis. 2011;9:246-8.

29. Sutherland LJ, Cash AA, Huang YJ, Sang RC, Malhotra I, et al. Serologic evidence of arboviral infections among humans in Kenya. Am J Trop Med Hyg. 2011;85:158-61.

30. Mease LE, Coldren RL, Musila LA, Prosser T, Ogolla F, et al. Seroprevalence and distribution of arboviral infections among rural Kenyan adults: a crosssectional study. Virol J. 2011;8:371.

31. Konongoi L, Ofula V, Nyunja A, Owaka S, Koka H, et al. Detection of dengue virus serotypes 1, 2 and 3 in selected regions of Kenya: 2011-2014. Virol J. 2016;13:182.

32. Baba M, Villinger J, Masiga DK. Repetitive dengue outbreaks in East Africa: a proposed phased mitigation approach may reduce its impact. Rev Med Virol. 2016;26:183-96.

33. Lutomiah J, Barrera R, Makio A, Mutisya J, Koka H, et al. Dengue outbreak in Mombasa City, Kenya, 2013-2014: entomologic investigations. PLoS Negl Trop Dis. 2016;10:e0004981.

34. Ngoi CN, Price MA, Fields B, Bonventure J, Ochieng C, et al. Dengue and Chikungunya virus infections among young febrile adults evaluated for acute HIV-1 infection in coastal Kenya. PLoS One. 2016;11:e0167508.

35. Amoakoh-Coleman M, Kayode GA, Brown-Davies C, Agyepong IA, Grobbee $D E$, et al. Completeness and accuracy of data transfer of routine maternal health services data in the greater Accra region. BMC Res Notes. 2015;8:114.

36. Adam JK, Abeyta R, Smith B, Gaul L, Thomas DL, et al. Clinician survey to determine knowledge of dengue and clinical management practices, Texas, 2014. Am J Trop Med Hyg. 2017;96(3):708-14.

37. Pond B, Sakka HE, Wamala J, Lukwago L. Mid-term evaluation of the integrated disease surveillance and response project. Manage Syst Int. 2011; http://pdf.usaid.gov/pdf_docs/Pdact326.pdf.

38. Christopher PR, David KV, John SM, Sankarapandian V. Antibiotic therapy for Shigella dysentery. Cochrane Database Syst Rev. 2010;(8):CD006784.

39. Zurovac D, Guintran JO, Donald W, Naket E, Malinga J, et al. Health systems readiness and management of febrile outpatients under low malaria transmission in Vanuatu. Malar J. 2015;14:489.

40. Steinhardt LC, Onikpo F, Kouame J, Piercefield E, Lama M, et al. Predictors of health worker performance after integrated Management of Childhood Illness training in Benin: a cohort study. BMC Health Serv Res. 2015;15:276.

41. Knebel E, Lundahl S, Raj HA, Ashton J, Wilson N. The use of manual job aids by health care providers: what do we know? Qual Assur Proj. 2000; https:// www.usaidassist.org/sites/assist/files/use_of_job_aids_qap_2000.pdf.

\section{Submit your next manuscript to BioMed Central and we will help you at every step:}

- We accept pre-submission inquiries

- Our selector tool helps you to find the most relevant journal

- We provide round the clock customer support

- Convenient online submission

- Thorough peer review

- Inclusion in PubMed and all major indexing services

- Maximum visibility for your research

Submit your manuscript at www.biomedcentral.com/submit

C Biomed Central 